\title{
Relaçôes do cotidiano: a pessoa com transtorno mental e sua rede de suporte social
}

| ${ }^{1}$ Mariana Moraes Salles, ${ }^{2}$ Sônia Barros |

Resumo: O presente estudo buscou conhecer a vida cotidiana de egressos de hospitais psiquiátricos que foram reinternados num período inferior a seis meses. Teve como objetivos conhecer a rede social desta população e analisar suas possibilidades de inclusão social. Foi utilizado o conceito de cotidiano de Agnes Heller como referencial teórico e o conceito de Reabilitação Psicossocial como categoria analítica da pesquisa. Foram realizadas 22 entrevistas semiestruturadas com pessoas com transtorno mental reinternadas em hospitais psiquiátricos e seus familiares, buscando investigar o cotidiano desta população no período entre internações. As entrevistas foram então submetidas à análise do discurso, que revelou que os usuários encontram dificuldades de inclusão social mesmo quando fora do hospital psiquiátrico. Foram relatadas a dinâmica de exclusão e inclusão dos usuários no núcleo familiar e as possibilidades e apoios sociais encontrados na comunidade. Recomenda-se um cuidado especial na atenção aos familiares, o combate ao preconceito e a atuação dos serviços em saúde mental, para facilitar a participação dos usuários em espaços comunitários.

\footnotetext{
1 Terapeuta Ocupacional, doutoranda em Cuidado em Saúde pela Escola de Enfermagem da Universidade de São Paulo (USP). Endereço eletrônico: marianasalles@uol. com.br.

2 Professor Livre-Docente do Departamento de Enfermagem Materno-Infantil e Psiquiátrica da Escola de Enfermagem da USP. Endereço eletrônico: sobarros@usp.br
} 
A partir da Reforma Psiquiátrica no Brasil, surgiram novas propostas de tratamento para o doente mental, em que a internação hospitalar deixa de ser o eixo central na atenção em saúde mental e os serviços substitutivos e a comunidade se apresentam como um novo espaço terapêutico. Neste contexto, se iniciam propostas para promover a inclusão social da pessoa com transtorno mental. A Reforma Psiquiátrica propõe que o foco do tratamento se desloque da doença para a pessoa em sofrimento psíquico e que a assistência deve ocorrer com o usuário vivendo em sua comunidade, evitando-se internações em hospitais psiquiátricos.

Os dados históricos mostram uma mudança em relação à assistência prestada ao doente mental, mas apesar das transformações que vem ocorrendo, ainda há internaçôes hospitalares (ALONSO, 2000). Segundo Barros e Bichaff (2008), apenas nos leitos do Sistema Único de Saúde (SUS) no Estado de São Paulo há 12.076 vagas para internação em hospitais psiquiátricos.

Para abordar este tema, optou-se por estudar a vida cotidiana de egressos de hospitais psiquiátricos, que foram reinternados após passar até seis meses vivendo na comunidade. Ao sair de uma internação em hospital psiquiátrico, o sujeito em sofrimento psíquico teve que estabelecer relacionamentos com as pessoas a sua volta, construir seu cotidiano e sua história de vida na sociedade à qual pertence. O usuário que retorna ao hospital psiquiátrico teve uma experiência de vida em que procurou retomar relações sociais e um lugar na sociedade.

O momento de ser liberado da instituição e voltar ao convívio social é esperado pelos internos, mas muitas vezes vem acompanhado da angústia sobre a incerteza de como será a vida na realidade externa, afinal, terá que assumir responsabilidades que não lhe são permitidas na instituição. É comum também que o interno tenha um status desfavorável ao sair da instituição, relacionado a um estigma social (GOFFMAN, 2003). Para a pessoa em sofrimento psíquico, esse é um momento crítico, pois precisará se inserir no mundo real, concreto, moldado por regras e valores. Ele irá conviver com seus familiares e vizinhos e deverá encontrar seu espaço, seus interesses e suas atividades diárias. Além disso, neste momento, ele é encaminhado para atendimento ambulatorial, ou para tratamento em regime de atenção semi-intensiva, onde deverá estabelecer novas relações e vínculos. 
A Reabilitação Psicossocial pressupõe que a comunidade e o tratamento sejam dimensões possíveis de propiciar a inserção social da pessoa com transtorno mental, mas o grande número de reinternaçôes em hospitais psiquiátricos aponta para dificuldades neste processo. Por isso, emerge a questão sobre o que acontece com o doente mental após uma internação. É importante conhecer como ocorre, ou não, a inserção social da pessoa com transtorno mental egressa de hospital psiquiátrico e quais as possibilidades de vida encontradas por essas pessoas na comunidade.

Assim, desenvolvemos este estudo ${ }^{1}$ com a finalidade de buscar compreender como se estabelecem as relações sociais das pessoas com transtorno mental que enfrentam o desafio de viver na sociedade e contribuir com a assistência destas pessoas, auxiliando no processo de sua alta e inserção social. Para atingir esta finalidade, os objetivos específicos foram conhecer a rede social desta população e analisar as possibilidades de inclusão social encontradas pelos sujeitos da pesquisa.

\section{Metodologia}

A abordagem qualitativa foi utilizada no processo metodológico desta pesquisa, buscando esclarecer as relações sociais que informam sobre o campo da saúde. Os conceitos de saúde são permeados por dimensões políticas e históricas, que consideram a abrangência das classes dominantes, a especificidade do sistema cultural, o modo de produção e as origens de costumes familiares, de vizinhança, de grupos etários, grupos de lazer e outros. O processo de saúde e doença é compreendido em complexa integração com aspectos biológicos, psicológicos, sociais e ambientais, estando em evidência a conexão entre o corpo individual e o social (MINAYO, 2004).

De acordo com esta orientação sobre saúde e metodologia qualitativa, optouse por fundamentar esta investigação no conceito de cotidiano de Agnes Heller, que considera que é na vida cotidiana que se produzem as relações sociais entre os homens, é na cotidianidade que o indivíduo se insere na sociedade, reproduzindo as atividades e cultura existentes (HELLER, 2000). Estar inserido na sociedade é organizar uma vida cotidiana capaz de conduzir a uma continuidade, em interação com os outros a sua volta e com o modo de produção da sociedade.

A vida cotidiana é a vida do homem inteiro, em todos os seus aspectos. $\mathrm{Na}$ cotidianidade, o homem apreende valores, realiza escolhas, comunica-se com os outros e torna-se apto a participar do grupo humano comunitário, movendo-se 
no ambiente social (HELLER, 2000). Pautado na vida cotidiana, o indivíduo se insere na sociedade, assimilando e participando do cotidiano da comunidade. As atividades do dia a dia de cada pessoa estão relacionadas com as atividades cotidianas de sua família, amigos, colegas de trabalho, constituindo uma trama de relaçôes sociais vinculadas às diferentes atividades do dia.

Foi utilizado o conceito de categorias analíticas e empíricas, as categorias analíticas "retêm historicamente as relações sociais fundamentais e podem ser consideradas balizadas para o conhecimento do objeto nos seus aspectos gerais. Elas mesmas comportam vários graus de abstração, generalização e de aproximação". As categorias empíricas são aquelas "construídas com finalidade operacional, visando ao trabalho de campo (a fase empírica) ou a partir do trabalho de campo. Elas têm a propriedade de conseguir apreender as determinaçôes e as especificidades que se expressam na realidade empírica” (MINAYO, 2004, p.94).

Como categoria analítica foi utilizado o conceito de Reabilitação Psicossocial, que considera como fundamental as circunstâncias em que vive a pessoa com transtorno mental e procura estabelecer melhores negociaçóes entre as necessidades dos usuários e as oportunidades do contexto (PITTA, 2001).

O decurso da psicose também está relacionado a condições ambientais, muitas vezes ligados a contextos microssociais, como a família e a comunidade, que são variáveis que podem ser modificadas e orientadas no processo de intervenção, que pressupõem um manejo ambiental. Nesse sentido, as pessoas com transtorno mental precisam articular o tratamento com a vivência na sociedade (SARACENO, 2001).

A presente pesquisa foi realizada em São Paulo, em um hospital especializado em psiquiatria, prestando atendimento a pessoas com transtorno mental em regime de internação. Apesar das melhorias e das tentativas de humanização do hospital, ainda é possível perceber traços de um modelo manicomial, marcado por uma acentuada estrutura normativa institucional.

Antes da coleta de dados, o projeto de pesquisa foi aprovado pelo comitê de ética do referido hospital e pelo Comitê de Ética da Escola de Enfermagem da Universidade de São Paulo. Além disso, os participantes da pesquisa foram informados sobre as finalidades, objetivos e metodologia da pesquisa e assinaram um Termo de Consentimento Livre e Esclarecido. Foi mantido sigilo em relação à identidade dos entrevistados. 
Foram sujeitos desta investigação pessoas com transtorno mental internadas no hospital psiquiátrico descrito e seus familiares. Na época da coleta de dados, o hospital contava com seis alas: três masculinas, uma feminina, uma ala para alcoolistas e dependência química e uma para moradores do hospital. A pesquisa foi realizada com usuários das alas masculinas e ala feminina, que contavam com 269 leitos ocupados. Os critérios para seleção das pessoas com transtorno psíquico que participaram da pesquisa foram: pessoas internadas no hospital há mais de um mês; que tenham sido reinternadas no período inferior a seis meses; conscientes, orientadas no tempo e espaço, capazes de manter um diálogo e que estivessem de acordo em participar da pesquisa.

Após busca nos prontuários, foram selecionadas 27 pessoas com transtorno mental, porém nem todos participaram da pesquisa, pois alguns não atendiam os critérios, outros tiveram alta antes de serem convidados para entrevista e alguns ainda se recusaram a participar da pesquisa. No total foram consideradas 13 entrevistas com pessoas com transtorno mental, entre 20 e 51 anos. Destes usuários, apenas nove familiares (entre 45 e 73 anos) concordaram em participar da pesquisa, totalizando 22 entrevistas.

Foram realizadas entrevistas semiestruturadas e a análise do discurso foi usada como forma de interpretação e apreensão da realidade apoiada no material coletado. Segundo Minayo (2004, p. 211), "ela visa a compreender o modo de funcionamento, os princípios de organização e as formas de produção social do sentido". O discurso é produzido no interior de instituições, de grupos, de um determinado contexto social e a partir de uma construção histórica. E segundo Vianna e Barros (2003), o homem é produto das relaçôes sociais e aprende a ver o mundo pelos discursos que assimila. O discurso é o lugar onde se pode observar a relação entre língua e ideologia, compreendendo-se como a língua produz sentidos por/para os sujeitos. O texto expressa ideologias, valores e crenças de uma sociedade em uma determinada época, nas suas condiçôes de existência.

Após a transcrição, leitura e releitura das entrevistas, o texto foi organizado em "frases temáticas imbuídas de afinidades em cada entrevista" (BARROS; EGRY, 2001, p. 105). Após esta etapa, os fragmentos foram agrupados pelos temas a que se referiam, reunindo os trechos temáticos similares de todos os depoimentos. O presente artigo se refere à categoria empírica relações pessoais. 


\section{Dificuldades encontradas no cotidiano do egresso de hospital de psiquiátrico}

As pessoas com transtorno mental entrevistadas relataram que quando saem do período de internação psiquiátrica, continuam a viver um cotidiano de segregação, encontrando dificuldades de interação com as pessoas a sua volta. Segundo Gaspari (2002), o homem não é um ser isolado, é um membro ativo e reativo de grupos sociais. A família é um grupo social natural, um sistema que faz parte de outros sistemas, que afetam a sua organização. A trama de relações sociais inclui, além da família, amigos e colegas; relaçôes que se estabelecem baseadas em diferentes atividades do cotidiano, como atividades sociais, culturais, esportivas, religiosas e de cuidados com a saúde.

As estruturas da vida cotidiana expressam e estabelecem os espaços de vida possíveis para estas pessoas. O cotidiano está relacionado não somente à evolução da doença, mas desempenha um papel ativo de construção psíquica e sóciocultural do indivíduo doente (GOLDBERG, 1998).

Muitas vezes o doente mental apresenta uma desorganização no fazer cotidiano que dificulta sua participação no mundo social e cultural. Os depoimentos relatam a falta de possibilidades, ausência de interesses, um cotidiano monótono, em uma circunstância de isolamento. Os discursos revelam, em um primeiro momento, falta do que fazer, não ter aonde ir, não ter com quem falar e a ausência de opções. São falas que demonstram certa paralisia ou apatia. Essa "falta" que aparece em todas as instâncias da vida é a marca da marginalidade, estar à margem da comunidade, é a marca da exclusão. Esse contexto ratifica a presença de uma rede social frágil, um contexto que favorece o isolamento, solidão e inação. Percebese a dificuldade em estabelecer um cotidiano que favorece a inclusão social e a seriedade com que deve ser considerado o fato de ocupar o tempo.

P 12 - Mas quando eu estou fora daqui, eu não saio muito, eu fico só em casa, na cama.

P 11 - Ah, eu fico em casa dormindo, fico deitando no sofá, vendo televisão.

FP 13 - Agora ele fica trancado dentro de um quarto, escutando o radinho, fumando o dia inteiro e aquilo abafado; sem se comunicar com ninguém. ${ }^{2}$

É importante questionar o significado desta inatividade e falta de relacionamentos, que não se apresenta como uma opção, por exemplo, de não trabalhar para construir uma vida tranquila, mas como uma diminuição de 
possibilidades de escolha. O fato de os entrevistados desenvolverem poucas

atividades influencia negativamente na constituição da rede social. Eles relataram que quase não têm amigos e que ficam muito tempo sozinhos, evidenciando uma rede social escassa e pouco estruturada.

P 13 - Não tenho mais (relacionamentos), não saio mais com ninguém.

P 7 - Não tenho turma nenhuma, eu sou um cara sozinho, solitário.

FP 13 - O M. não tem amigos. E ele reclama porque ele não tem amigos.

Foi relatada a dificuldade de comunicação que ocorre entre os familiares, o que dificulta a integração no núcleo familiar. Frente às dificuldades de convivência, não conversar é uma forma de se afastar e não ter que lidar com o familiar doente. Entende-se a "comunicação como um subsídio fundamental para possíveis mudanças nas concepçôes e representações dos familiares em relação aos transtornos mentais" (MELMAN, 1998, p. 182).

P 10 - Eu telefono pra ela (irmã), ela nunca responde, né?

P 7 - É muito sem refinamento... Muito rústico o relacionamento. "Como está a mãe?", "benção" e "tchau". Sem afinidade nenhuma.

FP 13 - E lá (em casa) ele não tem mesmo ninguém que converse; meu marido também não tem muita paciência de estar conversando, né.

Da mesma forma que um contato leva a outro, constituindo a rede social, a ruptura de um contato leva a outras rupturas, desestruturando a trama da rede social. Esta rede social frouxa, relatada pelos usuários e familiares, é uma forma de segregação; mesmo vivendo na comunidade o usuário continua excluído.

Os usuários relatam sua perda de poder contratual, o lugar do louco que é desvalorizado, motivo de chacota e zombaria. De acordo com Kinoshita (2001, p. 55), no universo social as "relaçóes de trocas são realizadas a partir de um valor previamente atribuído para cada indivíduo dentro do campo social, como pré-condição para qualquer processo de intercâmbio. Este valor pressuposto é o que lhe daria o seu poder contratual". O doente mental é visto como um estranho, diferente e incompreensível. A pessoa com transtorno mental que se sente desvalorizada se afasta, aumentando a tendência ao isolamento. Colocar o outro em um lugar de inferioridade é uma forma de segregação social. Esta forma de se relacionar com o doente mental está associada a pressupostos constituídos historicamente a partir da lógica manicomial. 
É no sentido de promoção de saúde que se confere a importância de estabelecer com as pessoas com transtorno mental uma relação horizontal, pois o problema não é a doença em si, mas determinar qual tipo de relação se instaura com o doente (BASAGLIA, 1985).

P 10 - Que o problema que eu tenho até é pra tirar sarro mesmo, que quem está nesse lugar aqui (hospital psiquiátrico); é motivo pra dar risada mesmo, né. Era pra eu não ligar, mas ligo pra essas conversas. Então eu não vou lá junto com eles.

P 5 - Aí, eles começaram a zoar, zoar. Aí, eles falaram: "por que não interna logo esse cara, meu?”. Eles me zoaram. Ficavam falando que o carro da polícia ia me pegar (para internar)...

As pessoas com transtorno mental que não têm casa, ou sua rede social é fraca, ou têm uma capacidade de produção social muito baixa, apresentam um poder de contratualidade que tende a zero. É baseado nas oportunidades de troca, no poder contratual do sujeito, que se cria espaço para a relação entre os membros da comunidade (SARACENO, 2001). A pessoa que é considerada doente mental recebe um atributo negativo, anuncia-se a sua invalidade e anula-se o seu poder de contrato. Seus bens são suspensos, suas mensagens incompreensíveis e seu afeto desnaturado, de forma que não há possibilidades de troca. Assim, o processo de reabilitação é um processo de restituição do poder contratual do usuário (KINOSHITA, 2001).

A partir desses relatos, é possível perceber que o tratamento não passa somente por uma assistência individualizada ao doente mental, é preciso ocorrer uma transformação na sociedade para que o fato de uma pessoa apresentar transtornos mentais não seja motivo de desvalorização e exclusão. É preciso haver um trabalho na comunidade para modificar a compreensão do que é a loucura e como ela pode ser tratada. A pessoa em sofrimento psíquico precisa de ajuda para aumentar o seu poder contratual e estabelecer relaçóes de igualdade. Nesse sentido, segundo Kinoshita (2001) a equipe de saúde mental pode intervir neste processo, "emprestando" poder contratual ao usuário, utilizando o seu prestígio, o saber reconhecido pela sociedade aos profissionais, para possibilitar relações e experiências renovadas aos usuários.

As pessoas com transtornos mentais precisam encontrar um lugar de respeito na sociedade, e este é um dos elementos fundamentais para sua real inserção na sociedade. Nesse sentido, a reabilitação psicossocial também significa reconstituir valor. 
Frente à escassez de relacionamentos, a família assume um importante papel na rede social do usuário, o que pode evitar o isolamento e a solidão. A família é a principal (ou única) referência da rede de relações pessoais próxima para as pessoas com transtorno mental, seu primeiro núcleo de inserção social.

P 11 - Não fosse pela minha avó, eu ficava sozinho em casa, porque meu irmão trabalhava, aí eu ficava sozinho dentro de casa.

A doença mental ativa uma série de respostas nas pessoas do seu grupo social, especialmente aquelas do convívio familiar. Os familiares ficam ansiosos por soluções, necessitando de auxilio para conviver no dia a dia com o doente mental e nem sempre encontram uma resposta na equipe de saúde mental (COLVERO, 2002).

A família é um sistema no qual podem ser encontrados subsistemas, dependendo de seu tamanho e definições de papéis. É um núcleo da sociedade que se encontra entrelaçado por relaçôes e oposiçôes que marcam o comportamento do indivíduo. A estrutura de uma família é constituída por normas de interação que se estabelecem entre seus membros, que organiza as relações dentro do sistema de forma dinâmica e recíproca. A presença de enfermidade incide sobre o grupo familiar; na maioria das vezes é a família que se responsabiliza pelos cuidados dos portadores de transtorno mental (OSINAGA, 2004).

Uma das primeiras barreiras a ser superada no processo de Reabilitação Psicossocial é a exclusão da pessoa com transtorno mental do ambiente familiar. Para Bertolote (2001, p.156), a Reabilitação Psicossocial é um processo de remover barreiras "que impedem a plena integração de um indivíduo na sua comunidade". Ao mesmo tempo em que existem os relatos de exclusão por parte dos familiares, a família também é apontada como uma referência para as pessoas com transtorno mental. É ela que cuida e constitui a rede social com a qual os usuários podem contar. Nessa perspectiva, é a família que oferece suporte material e afetivo para a vida da pessoa com transtorno mental na sociedade, a família empresta poder contratual ao usuário.

P 12 - As pessoas importantes são as que estão mais perto de mim, a toda hora, a todo instante que vai passando minha vida, é minha própria família.

P 9 - O relacionamento com família é bom porque eu gosto deles. Ela (mãe) cuida de mim, né? Faz minha comida. 
O depoimento das mães esclarece esta dinâmica de exclusão e inclusão familiar. Em geral, os parentes mais próximos, mães e avós, assumem a responsabilidade e os cuidados com a pessoa com transtorno mental, e o incluem na família. Já a família expandida, como tios e em alguns casos irmãos, muitas vezes rejeitam e excluem o usuário, formando subsistemas familiares.

As mães relatam que são excluídas junto com os filhos; ao mesmo tempo em que emprestam poder contratual para o usuário, têm a sua rede social diminuída, pois muitas também são segregadas. Segundo Colvero (2002), a família também fica sujeita à condição de isolamento; há uma redução de contatos e a renúncia do prazer e divertimento. A família se distancia do corpo social, deixando de comparecer a festas e restringindo as visitas. Juntamente com o isolamento, a família vivência sentimentos de raiva, culpa, vergonha, isolamento e solidão relacionados ao preconceito e estigma social da doença.

FP 13 - Vou falar uma coisa, com os irmãos também não posso contar, quando ele está em casa não vão visitar.

FP 4 - Eu fico triste... Meus irmãos não gostam do meu filho, podiam me ajudar e não me ajudam, ninguém me ajuda, ninguém quer saber. Os outros se afastam de mim por causa do N.! Bastante, bastante...

Manter o portador de doença mental no lar significa reduzir o círculo das relações familiares; o convívio com a doença impõe um desgaste emocional (OSINAGA, 2004). De acordo com Gobbo (2004), a família é cuidadora e fonte de apoio às pessoas, precisando também de cuidados por parte dos profissionais da saúde. Ajudar os familiares na gestão da vida cotidiana com os usuários contribui para aliviar o peso dos encargos, facilita o processo de estabelecimento de cooperação, diminui os fatores estressantes ativadores de situaçóes de crise e estimula a criação de possibilidades participativas, melhorando a qualidade de vida de todas as pessoas envolvidas (MELMAN, 1998, p. 58). Uma das propostas dos serviços de Reabilitação Psicossocial é justamente realizar esse suporte aos familiares.

Os discursos revelam que os usuários requerem atenção e cuidados no cotidiano. Alguns familiares se colocam disponíveis, modificando a sua rotina, priorizando o cuidar e o estar com o familiar com transtorno mental. Muitas vezes os familiares reorganizam seus papéis e "o paciente passa a ser o centro das atençôes e cuidados” (MORENO, 2001, p. 73).

FP 13 - Quando o M. está em casa, aí eu tenho mais o cuidado de ficar mais um pouco em casa com ele. Porque o M. é que nem uma criança. 
FP 9 - Ele é um amorzinho, mas, assim, ele quer que você fique dando atenção o

tempo todo pra ele. Então, e eu tinha que ficar em casa, pra dar o remédio pra ele.

Três vezes ao dia.

Também foi relatado que o cuidado com a pessoa com transtorno mental impede ou dificulta a continuidade do familiar no trabalho, o que é entendido como uma realidade penosa para os familiares. Considera-se desvantagem possuir uma pessoa com problemas mentais na família, pois dificultaria a inserção e permanência dos familiares no mercado de trabalho. Desta forma, a situação socioeconômico desta população muitas vezes produz dificuldades no processo de Reabilitação Psicossocial.

FP 9 - Agora eu estou em casa, queria muito trabalhar pra ajudar, mas com o T. desse jeito, como é que eu vou fazer, né? Está difícil, está difícil cuidar do T. e trabalhar fora, eu não tenho condições.

As famílias também se queixam, pois a maior parte dos usuários não trabalha e não estuda. Os familiares se sentem sobrecarregados, assumindo sozinhos todas as responsabilidades para sustentar a casa.

FP 8 - Eu gostaria que ele ajudasse; não trabalhar, eu não obrigo ele procurar emprego, eu sei que ele não... Mas vai estudar, né? Ocupar a cabeça; fica o dia todo sem fazer nada, só coisa ruim passa pela cabeça.

Foi relatado que o familiar vive sob tensão, e é nesse sentido que a internação se apresenta como um alívio, por um intervalo de tempo eles não serão mais responsáveis pelo que possa acontecer a pessoa com transtorno mental. Quando o usuário está internado, os familiares relatam que podem descansar, viver com tranquilidade e ter mais tempo para si próprios. Assim, a ideia de que a pessoa em sofrimento psíquico deve permanecer no hospital psiquiátrico se fortalece.

FP 4 - Quando ele está internado, me dá um descanso, porque em casa não é fácil. Esses meses que ele está internado foi uma benção. Quando ele está em casa, eu não tenho sossego, é só preocupação.

As famílias relatam o quanto é difícil conviver e cuidar do doente mental, expressam o seu estresse e suas fragilidades. Isto indica a importância que deve ter a inclusão da família na assistência prestada pelos serviços de saúde.

De acordo com Melman (1998, p. 3), o surto psicótico de um membro da família representa a incapacidade de cuidar adequadamente do outro, "o fracasso de um projeto de vida, o desperdício de muitos anos de investimento e dedicação. A doença mental continua sendo com frequência motivo de vergonha para os familiares". 
Sendo a família o primeiro núcleo que estabelece uma relação de interação com o portador de transtorno mental, faz-se necessário o cuidado com ela. Se a proposta da Reabilitação Psicossocial é tratar o doente mental na comunidade, a família faz parte do ambiente social do usuário e é um importante elo com outros espaços sociais. A família precisa encontrar formas de conviver com o doente mental sem ser destruída, sem que isto constitua a interrupção ou paralisação da sua vida, e as equipes de saúde podem auxiliar neste processo.

\section{Constituição da rede social de suporte}

Também foram relatados pelos usuários os apoios encontrados na sociedade, ou a falta de apoio. Por um lado, alguns familiares relatam não receber nenhum tipo de apoio ou ajuda, não tem com quem contar, estando sozinhos nos cuidados com os usuários. Neste sentido, o processo de Reabilitação Psicossocial pode encontrar obstáculos relacionados ao contexto em que vivem os usuários e a falta de suporte disponível.

FP 13 - (Sobre ajuda na comunidade ou família) Não, é eu e eu mesmo.

FP 3 - (Sobre apoio na comunidade ou ONG) Não, ainda não. Eu estava precisando, mas não tive ainda não.

Por outro lado, a família expandida pode constituir suporte em alguns casos, principalmente em relação à questão financeira, uma ajuda que faz parte da rede de relaçôes pessoais das cuidadoras e que auxiliam nos cuidados com o familiar com problemas mentais devido ao apoio material.

FP 11 - Às vezes, você não consegue remédio, tem que comprar. Aí, nós (família) vamos fazendo uma "vaquinha". É uma luta.

FP 8 -É, eu tenho uma irmã e três sobrinhos, então eles me ajuda (financeiramente). Um pouco, mas ajudam.

Os vizinhos também representam uma referência para algumas famílias, há uma solidariedade no bairro, mais uma vez, a ajuda é oferecida para as cuidadoras, como parte de sua rede social. Elas estabelecem no bairro uma relação de troca de favores, de amizade, contam com o empréstimo de um transporte para ir ao hospital; alguém de fora da família para conversar com o usuário, auxiliar a administrar a medicação; um lugar para ir quando a convivência com o usuário está difícil. 
As cuidadoras também ajudam os vizinhos com o que podem, é uma relação

de vizinhança em que um sabe das dificuldades que o outro passa e se dispõe a ajudar, em um sistema de troca.

FP 9 - Ainda bem que tem gente boa nesse mundo, a minha vizinha falou assim, eu vou ficar lá com ele. Engraçado, comigo ele não ficava, mas a minha vizinha tem um jeito legal de conversar, aí chegou conversando, levando ele com jeito.

FP 7 - Apesar das pessoas fugirem, quantas vezes a gente já não tive ajuda, entende? Te leva pra você estar no hospital rápido. Te faz um favor.

FP 2 - Deus me abençoe e a eles (vizinhos) também. Porque quando eu preciso, eu chamo eles, porque eu não tenho ninguém que possa, né, me socorrer. Então, eu ajudo eles também, porque são desempregados.

Os discursos também revelam situações em que a rede social possibilitou a entrada no mercado de trabalho ou suporte material, como alimentos. Essa trama de relacionamentos muitas vezes vai além dos contatos pessoais mais próximos, formando uma rede social expandida, que melhora as possibilidades de inserção social.

Castel (1999) define como sociabilidade primária o sistema de regras que ligam diretamente os membros de um grupo a partir de seu pertencimento familiar, da vizinhança, do trabalho e que tecem redes de interdependência sem a mediação de instituiçóes específicas. Nesse sentido, a família e a comunidade tendem a funcionar como um sistema autorregulado, que recompõe um equilíbrio utilizando seus próprios recursos.

P 10 - Eu falei (para o vizinho), arruma um serviço pra mim. Eu falava todo o dia. Ele arrumou mesmo pra mim. De tanto eu falar pra ele...

P 6 - As pessoas trás comida para nóis comer em casa, nunca faltou o arroz, o feijão, o café, e trás até cesta básica. Os paulistas são gente boa, quando as pessoas está com fome, eles não deixa morrer de fome.

No relato que segue, uma mãe relatou sua experiência em uma organização não-governamental. É uma associação que surgiu pelo investimento de profissionais de saúde mental e familiares, é independente, sem estar ligada ou receber recursos de outra instituição, e passa por dificuldades financeiras para se manter. A principal atividade desta associação é vender objetos produzidos pelos usuários em serviços de saúde ou objetos de brechó em uma praça. O suporte oferecido pela associação é considerado complementar a assistência encontrada nos serviços substitutivos. 
Em algumas organizações não-governamentais, os usuários e familiares deixam de ser apenas "objeto de intervenção técnica para assumir, de fato, o papel de agentes transformadores da realidade, opinando e participando ativamente das discussões sobre políticas de saúde mental” (MELMAN, 1998, p. 185).

FP 7 - Ah, a Associação da qual eu faço parte no fundo, com aquela esperança, né? Que os pacientes trabalhavam (no brechó, reciclagem de latas e venda de produtos artesanais), ganhavam o seu dinheirinho, é pra isso, é pra independência, se eles verem a finalidade é essa, né?

A frase que segue desvela que quando a atividade gera renda, esta ocupação recebe outro valor, deixa de ser entretenimento e passa ser uma atividade significativa, que aumenta o poder contratual do usuário.

FP 7 - Porque uma pessoa assim que trabalha, que tem uma atividade real, não é uma atividade pra ocupar o tempo, é bem diferente, uma pessoa que tem uma atividade e que ela recebe um dinheirinho, é um incentivo, né? Então, ela desabrocha mais, se sente útil, ou se sente menos pesado, né?

É preciso que as pessoas da rede social do usuário possam o ver enquanto sujeito que merece respeito e apoio, como acontece no caso desta associação que pretende auxiliar o usuário a estabelecer relaçôes de troca. O transtorno mental consiste em uma situação problema que põe em movimento um complexo processo social. "O aparecimento de uma doença mental pode ser pensado tanto como um fenômeno individual como fenômeno da rede social” (REINALDO, 2003 , p. 28). As redes que cercam a pessoa doente influenciam na definição do problema, nas escolhas sobre as formas de assistência e na avaliação dos resultados das ações terapêuticas. Os significados de tratamento e cura são sustentados e confirmados pela elaboração de imagens constituídas pelas redes sociais.

Nestes discursos, foi possível desvelar a contradição que ocorre no processo de exclusão e inclusão das pessoas com transtornos mentais. Por um lado, há a prevalência da lógica manicomial; por outro, também é possível constatar a constituição da lógica da inclusão, tanto nos relatos em que os vizinhos incluem a família do doente mental numa rede de apoio e trocas, como no relato desta mãe, que participa de uma associação que procura promover um lugar de inclusão social para o portador de transtorno psíquico.

Nesse sentido, Saraceno (2001) já alertava para o contexto em que se realiza a prática da reabilitação psicossocial, que apresenta variáveis relacionadas ao usuário, a sua família, ao serviço que presta assistência e a comunidade. As 
variáveis sociais e situacionais têm um peso importante no processo reabilitativo.

O principal aspecto que muda de um contexto para o outro é a passagem da lógica manicomial, para a lógica da inclusão. Na lógica da inclusão, a comunidade é um recurso a ser utilizado pelas equipes de saúde, torna-se uma riqueza.

As instituiçôes formais da comunidade e as informais representam recursos potenciais de um serviço: da paróquia ao sindicato, das associaçóes esportivas às agregações mais ou menos formalizadas dos cidadãos, a rede de lugares, recursos, oportunidades é infinita e infinitas são as articulações individuais serviço/paciente/comunidade, capazes de produzir sentido de contratualidade e bem-estar (SARACENO, 2001, p. 103).

O trabalho com pessoas (usuários, famílias, comunidade) gera conflitos, o hospital psiquiátrico silencia os conflitos, a desinstitucionalização representa liberação e escuta do conflito, o usuário não é mais recluso, a família aliviada, a comunidade tutelada. A psiquiatria não entra em consenso com a família e a comunidade, mas é “desafiada a 'negociar' entre interesses diversos, para garantir não mais ausência de conflito, mas o seu governo" (SARACENO, 2001, p. 107).

A riqueza que representa a comunidade ainda está pouco mobilizada a favor da lógica da inclusão do usuário, a relação entre a equipe dos serviços substitutivos ou do próprio hospital psiquiátrico com a comunidade necessita de maior investimento para o processo de construção de um cotidiano do doente mental inserido na sociedade.

\section{Considerações finais}

A rede social nos informa sobre quem somos nos oferece uma resposta a nossa forma de estar no mundo, e o olhar do outro nos informa sobre nossa forma particular de ser. Existe uma correlação entre a qualidade da rede social e a qualidade da saúde; a pobreza das relações sociais constitui um risco para a saúde. Existem evidências de que quando estamos doentes, a presença de membros da família auxilia como redutor do estresse. As relações sociais organizam a identidade, contribuem para dar sentido à vida de seus membros (SLUZKI, 1997).

Os serviços em saúde mental precisam refletir sobre como ocorre a interação dos usuários na comunidade. É aconselhável que as internações ocorram nos hospitais gerais, na tentativa de diminuir o estigma que acompanha a pessoa com transtornos mentais após sua saída dos hospitais psiquiátricos. As internações, quando imprescindíveis, devem ser breves e deve-se facilitar a visita das pessoas da comunidade aos usuários, na tentativa de que a internação não seja uma 
ruptura dos laços sociais. Após a internação, o processo de alta do usuário deve ser alinhavado com o encaminhamento para outros serviços de saúde e devem ser realizadas orientações aos familiares para o acolhimento e recepção do usuário. Caso ocorra a internação, ela não deve representar uma ruptura nas possibilidades de Reabilitação Psicossocial dos usuários, mas fazer parte do processo que ajuda a comunidade a criar novas formas de lidar com o transtorno mental.

Os serviços de saúde mental em regime aberto podem estabelecer programas específicos e condutas direcionados para acolher e ajudar os familiares dos usuários. Esta pesquisa ressaltou o quanto os familiares são um elemento central na inclusão social dos usuários e por isso merecem atenção especial dos serviços, não apenas como informantes sobre a situação e os sintomas dos usuários, mas como pessoas que necessitam de ajuda e suporte para conviver com usuário.

Estes serviços também podem atuar como facilitadores da participação dos usuários em ambientes da comunidade como academias de ginástica, clubes, igreja, associações de bairro, centros culturais e outros. Este objetivo pode ser atingido a partir de convênios entre os serviços de saúde e outras instituições ou a partir do projeto terapêutico individual de cada usuário. Além disso, combater o estigma se apresentou como um elemento fundamental para possibilitar a inclusão social do usuário e sua família, abrindo espaços para que eles circulem nos ambientes comunitários. Neste sentido, pode ser útil realizar campanhas contra a discriminação da pessoa com transtorno mental na mídia e nas instituições públicas, como nos serviços de saúde e escolas.

Por mais difícil que seja para esta população construir a sua vida cotidiana e se relacionar com familiares, amigos e vizinhos, estes são aspectos centrais para que eles consigam romper o ciclo de reinternações em hospital psiquiátrico e construir sua vida inserida na sociedade.

\section{Referências}

ALONSO, S.G. Falando sobre reinternação psiquiátrica: a voz das pacientes. 2000. 96 p. Dissertação (Mestrado em Enfermagem Psiquiátrica) - Escola de Enfermagem, Universidade de São Paulo, São Paulo, 2000.

BARROS, S.; BICHAFF, R. Desafios para desinstitucionalização: censo psicossocial dos moradores de hospitais psiquiátricos do Estado de São Paulo. São Paulo: FUNDAP, 2008. 170p. 
BARROS, S.; EGRY E.Y. O louco, a loucura e a alienação institucional: o ensino de enfermagem sub judice. Taubaté: Cabral, 2001. 197 p.

BASAGLIA, F. A Instituição negada: relato de um hospital psiquiátrico. Rio de Janeiro: Graal, 1985. 362 p.

BERTOLOTE, J.M. Em busca de uma identidade para a Reabilitação Psicossocial. In: PITTA, A. (Org.). Reabilitação psicossocial no Brasil. São Paulo: Hucitec, 2001. p. 155-58.

CASTEL, R. As metamorfoses da questão social: uma crônica do salário. Petrópolis: Vozes; 1999. $611 \mathrm{p}$.

COLVERO, L.A. Desafios da familia na convivência com o doente mental: cotidiano conturbado. 2002. 111 p. Tese (Doutorado em Enfermagem Psiquiátrica) - Escola de Enfermagem, Universidade de São Paulo, São Paulo, 2002.

GASPARI, V.P.P. Rede de apoio social e tentativa de suicídio. 2002. 146 p. Dissertação (Mestrado em Ciências Médicas) - Faculdade de Ciências Médicas, Universidade Estadual de Campinas, Campinas, 2002.

GOBBO, A.F.F. Conhecimento do familiar da pessoa em sofrimento psíquico sobre a terapêutica medicamentosa. 2004. 73 p. Dissertação (Mestrado em Enfermagem Psiquiátrica) - Escola de Enfermagem de Ribeirão Preto, Universidade de São Paulo, Ribeirão Preto, 2004.

GOFFMAN, E. Manicômios, prisões e conventos. São Paulo: Perspectiva, 2003. 156 p.

GOLDBERG, J.I. Cotidiano e instituição: revendo o tratamento de pessoas com transtorno mental em instituições públicas. 1998. 756 p. Tese (Doutorado em Medicina Preventiva) Faculdade de Medicina, Universidade de São Paulo, 1998.

HELlER, A. O cotidiano e a história. São Paulo: Paz e Terra, 2000. 121 p.

KINOSHITA, R.T. Contratualidade e reabilitação psicossocial. In: PITTA, A. (Org.). Reabilitação psicossocial no Brasil. São Paulo: Hucitec, 2001. p. 55-59.

MELMAN, J. Repensando o cuidado em relação aos familiares de pacientes com transtorno mental. 1998. 212 p. Dissertação (Mestrado em Medicina Preventiva) - Faculdade de Medicina, Universidade de São Paulo, 1998.

MINAYO, M.C.S. O desafio do conhecimento: pesquisa qualitativa em saúde. São Paulo: Hucitec, 2004. 269p.

MORENO, V. Vivência do familiar da pessoa em sofrimento psíquico. 2001. 173 p. Tese (Doutorado em Enfermagem Psiquiátrica) - Escola de Enfermagem de Ribeirão Preto, Universidade de São Paulo, Ribeirão Preto, 2001.

OSINAGA, V.L.M. Estudo comparativo entre os conceitos de saúde e de mental e a assistência psiquiátrica, segundo portadores e familiares. 2004.137 p. Tese (Doutorado em Enfermagem Psiquiátrica) - Escola de Enfermagem de Ribeirão Preto, Universidade de São Paulo, Ribeirão Preto, 2004. 
PITTA, A. O que é Reabilitação Psicossocial no Brasil, Hoje? In: . (Org.).

Reabilitação psicossocial no Brasil. São Paulo: Hucitec, 2001. p. 19-28.

REINALDO, A.M.S. O itinerário terapêutico em saúde mental pela história oral de vida de um paciente psiquiátrico. 2003. 118 p. Dissertação (Mestrado em Enfermagem Psiquiátrica) Escola de Enfermagem de Ribeirão Preto, Universidade de São Paulo, Ribeirão Preto, 2003.

SARACENO, B. Libertando identidades: da reabilitação psicossocial à cidadania possível. Rio de Janeiro: TeCorá, 2001. 175 p.

SLUZKI, C.E. A rede social na prática sistêmica. São Paulo: Casa do Psicólogo, 1997.

VIANNA, P.C.M.; BARROS, S. Análise do discurso: uma revisão teórica. REME, Belo Horizonte, v. 7, n. 1, p. 56-60, 2003.

\section{Notas}

${ }^{1}$ Texto elaborado a partir da dissertação de mestrado Internação em hospital psiquiátrico: o (des) caminho para vivência do cotidiano e da inserção social, da Escola de Enfermagem da Universidade de São Paulo.

${ }^{2}$ A letra "P" significa paciente e "P1" se refere ao paciente entrevistado número 1, até paciente entrevistado número 13. As letras FP se referem ao familiar do paciente e "FP1" significa familiar do paciente número 1 . 


\section{Everyday life relationships: people with mental} health problems and their social network

This study analyzed everyday life of patients who had been discharged from a psychiatric hospital and were readmitted in a period of less than six months. It aimed to know this population's social network and analyze their possibilities of social inclusion. The everyday life concept of Agnes Heller was used as a theoretical basis and the Psychosocial Rehabilitation concept was used as an analytic category. It comprised 22 semistructured interviews with people with mental health problems readmitted in a psychiatric hospital and their relatives, seeking explore the everyday life of this population in the period between admissions. The interviews were submitted to discourse analysis, which revealed that the users find difficulties in social inclusion even when they are outpatients, it expresses the users social exclusion and inclusion dynamic in the family and the possibilities and social support found in the community. It recommends especial attention to patients' family care, fighting prejudice, and the work of mental health services to facilitate the user participation in community spaces.

Key words: mental health, everyday life, social inclusion and social network. 